\title{
A música como instrumento para o ensino de geografia e seus conceitos fun- damentais: pensando em propostas para o trabalho em sala de aula
}

\author{
Lucas Labigalini Fuini ${ }^{1}$ \\ Juliana Lopes Dos Santos ${ }^{2}$ \\ Camilla Andréa Damião ${ }^{3}$ \\ Patrícia De Oliveira ${ }^{4}$ \\ Gabriel Rios ${ }^{5}$
}

${ }^{1}$ Professor Assistente Doutor do Curso de Geografia da Unesp - Campus de Ourinhos/SP. Endereço: Av. Vitalina Marcusso, 1500, Bairro Campus Universitário, CEP: 19910-206, Ourinhos - SP.E-mail: lucasfuini@ourinhos.unesp.br

Recebido em 04/2012. Aceito para publicação em 12/2012.

Versão online publicada em 01/02/2013 (http://seer.ufrgs.br/paraonde)

\begin{abstract}
Resumo: O presente ensaio buscará explorar um assunto essencial no ensino de Geografia para jovens: o processo de construção e apreensão de conceitos. Utilizando uma base teórica sócio construtivista, este estudo compreende que o aprendizado de conceitos geográficos está diretamente associado à formação de uma consciência espacial através do diálogo, interação e reflexão do aluno com seu espaço de vivência. E esses dois elementos - a consciência espacial e o espaço de vivência - podem ser mobilizados com o uso de letras de músicas em situações de aprendizagem. 0 artigo explorará inicialmente alguns aportes teóricos sobre o ensino de Geografia e suas novas concepções e as possibilidades dadas ao ensino de conteúdos geográficos com o uso de músicas. Com os indicativos das diretrizes educacionais vigentes em âmbito nacional, destaca-se a importância do estudo de conceitos como eixos do conhecimento e da aprendizagem e, nesse caminho metodológico, faz-se a proposição de um conjunto de letras musicais agrupadas por fichas de atividade válidas para o estudo de conceitos geográficos em turmas de Ensino Médio, letras essas que discorrem sobre lugares, regiões, territórios e paisagens diversas, trazendo os elementos cotidianos atrelados às relações sociais materializadas no espaço geográfico.
\end{abstract}

Palavras-chave: Ensino de Geografia. Construção de conhecimentos. Conceitos. Música.

\section{Introdução}

Segundo Damiani (1999), a cidadania refere-se à materialização de relações de diferentes ordens, sendo que sua discussão relaciona-se à interpretação do lugar e do espaço, demanda inerente ao ensino geográfico. Vesentini (1999) postula que a escola e o ensino de Geografia podem ser instrumentos de libertação para o aluno se auxiliálo no desenvolvimento do pensamento crítico, por meio da inovação e criatividade, colocando-o como agente das transformações sociais na conquista da cidadania. Cavalcanti (1998), por sua vez, afirma que a Geografia tem grande relevância na prática social cotidiana, para a formação de uma consciência espacial e para uma relação ética e estética com o espaço de vivência.

Por estas três afirmações iniciamos este artigo defendendo a ideia de que o ensino de Geografia, em seus objetivos de construção de uma consciência espacial, interpretação do lugar e conquista da cidadania pelos educandos, não pode deixar de envolver a aprendizagem sobre os conce- itos geográficos, elementos essenciais para o entendimento de fenômenos e fatos sociais e econômicos e sua concretização em paisagens, territórios e lugares.

Além disso, esse aprendizado de conceitos, para se tornar mais atraente e significativo ao aluno, pode partir do entendimento das representações sociais dos alunos, propiciando a atividade mental e física aos mesmos em situações de cooperação e interação (CAVALCANTI, 1998).

Assim, a música - com suas letras - se coloca como instrumento importante e favorável à discussão e reflexão coletiva em sala de aula sobre conceitos da Geografia, estimulando a estruturação de conceitos científicos em conceitos escolares através da observância de dois elementos: cotidiano/vivência do aluno e a relação dialógica alunoprofessor-aluno.

As letras musicais, por seu conteúdo rico, popularidade e atualidade, estimulam o aprendizado de conteúdos geográficos, pois instigam os alunos ao interesse pela descoberta do novo e dão ao professor outros meios para realizar seu papel de 
intervenção na aprendizagem, problematizando e reconstruindo os conteúd os aprendidos na escola.

0 presente artigo se organiza, portanto, em três partes principais: a primeira visa discutir a importância de um ensino de Geografia pautado na construção de conceitos; a segunda explora a relação entre música e ensino de Geografia; e a terceira e última expõe algumas sugestões de práticas didático-pedagógicas que fazem uso de letras musicais como ferramentas para o ensino-aprendizagem de conceitos geográficos e escolares.

\section{A construção de conceitos no ensino de Geografia}

Os Parâmetros Curriculares Nacionais (PCN), tanto no Ensino fundamental de 5a a 8 $^{\text {a }}$. série quanto no Ensino médio, apontam como um problema do ensino atual de Geografia o abandono de conteúdos fundamentais, como os conceitos/categorias de território, lugar e paisagem.

Os objetivos de área do PCN de Ensino fundamental/EF (1998) para o segundo e terceiro ciclos (jovens de 11 a 14/15 anos) colocam a importância de: conhecer o mundo atual em sua diversidade entendendo como as paisagens, lugares e territórios se constroem; conhecer o funcionamento da natureza em suas múltiplas relações e da sociedade na construção do território, da paisagem e do lugar; conhecer e saber utilizar procedimentos de pesquisa da Geografia na paisagem, território e lugar; perceber na paisagem local e no lugar em que vivem as manifestações da natureza e sua apropriação pela ação da coletividade. (PCN, 1998)

No PCN-Ensino médio/EM (jovens de 15 a $17 / 18$ anos), em suas orientações complementares, coloca-se a importância de se superar, na Geografia escolar, uma abordagem pautada nos conteúdos para uma preocupação com os conceitos e seu alcance. Nesse sentido, destacam-se os seguintes conceitos: espaço geográfico, paisagem, lugar, território, escala e globalização (com as noções subsidiárias de técnicas e redes). Afirma-se, no documento, que a opção por conceitos é essencial para que seja superada a visão de uma Geografia descritiva, meramente informativa, pela de uma disciplina que fomente a construção do conhecimento de forma reflexiva e dinâmica, permitindo a criatividade e dando condições ao aluno para entender o dinamismo que rege a organização e evolução das sociedades. Portanto, o eixo estruturador do processo de ensino-aprendizagem, baseado em competências, deveria ser o trabalho com os conceitos geográficos.

Castellar (2000) afirma que o ensino de Geografia deve dar ênfase à construção de concei- tos pela ação da criança, tomando como referência as suas observações do lugar de vivência para, a partir daí, se formalizar conceitos geográficos, utilizando, por exemplo, a linguagem cartográfica. Em sua concepção, alfabetizar em Geografia significa contextualizar o aluno, cercá-lo do conteúdo geográfico e ir além da transmissão clássica de conteúdo baseada em uma visão compartimentada e não relacional.

Cavalcanti (1998) postula que a construção de conhecimentos geográficos na escola deve partir da compreensão do papel do espaço nas práticas sociais e da influência dessas práticas sociais nas configurações do espaço. 0 pensar geográfico deveria contribuir para a formação do cidadão que contextualiza espacialmente os fenômenos, conhece $o$ mundo e age como ator social. Nesse sentido, a autora apresenta quatro constatações sobre o ensino de Geografia e, particularmente, do ensino de conceitos geográficos:

- o problema no ensino-aprendizagem geográfico está na dificuldade de se formar um raciocínio geográfico, pois não há o estabelecimento da relação entre os conteúdos da Geografia e a prática social diária dos alunos;

- A questão crucial é como estruturar conceitos científicos em conceitos escolares;

- Um dos caminhos para a compreensão dessa questão é o estudo da representação social dos alunos a respeito de temas e conceitos trabalhados na Geografia escolar;

- O professor deve propiciar condições para que o aluno possa formar ele mesmo um conceito, pois memorização e associação por si só não propiciam a formação de conceitos.

Compartilhamos, portanto, da perspectiva teórica de Cavalcanti (1998) que subsidia sua análise do processo de construção de conhecimentos na escola. A autora propõe metodologias baseadas no sócio construtivismo. 0 suporte teórico de sua metodologia é a Psicologia Histórico-cultural de Vygotsky. Na concepção sócio construtivista, o ensino escolar é o processo de conhecimento do aluno mediado pelo professor e o objetivo maior do ensino passa a ser o processo de aprendizagem do aluno. 0 papel do docente é articular os objetivos, conteúdos e métodos que levem em conta a realidade dos alunos.

\section{O uso da música no ensino de Geografia}

A música, com suas letras e ritmos, aparece como uma das possíveis linguagens que podem ser utilizadas para propiciar a aprendizagem significativa e crítica de conceitos geográficos, mobilizando 
as dimensões lúdicas e reflexivas do processo educativo.

Segundo Viana (2000), a música é um veículo de expressão que atinge os jovens nas práticas docentes. É possível estudar nosso cotidiano através de letras de músicas populares e habituais dos jovens, estabelecendo relações sociais e espaciais a partir delas. A análise de letras de canções oferece um instrumental a mais no auxílio ao professor em seu processo pedagógico de sistematizar conteúdos de forma criativa.

Segundo Mesquita (1994), através das letras das canções é possível desvelar todo um universo social construído através do imaginário coletivo da sociedade, que nos auxilia a melhor compreender quem somos no contexto de nossa contemporaneidade e do passado recente de que fomos partícipes. (VIANA, 2000, p. 109).

Oliveira; Silva, et alii (2005) afirmam que a música, como um meio de comunicação, pode ser considerada um apoio pedagógico e instrumento facilitador na superação de algumas barreiras do processo de ensino-aprendizagem, criando situações em que o aluno se sinta atraído pelas propostas do professor e o mesmo seguro para propor situações de aprendizagem sobre determinados conteúdos.

Quando a proposta de utilização da música é apresentada aos alunos, a tendência que se observa é a de serem tomados pela curiosidade e ansiedade. A receptividade é quase sempre satisfatória. Tal iniciativa facilita muito na concentração e absorção das ideias explicitadas pela obra musical, complementando o uso do livro didático. Após a iniciativa do professor, sua argumentação e reflexão sobre ideias apreendidas com o auxílio da música, partese para a segunda etapa da proposta aqui apresentada. Sugere-se, então, que o professor estimule cada aluno a escolher a sua própria música, a partir de um tema previamente proposto e elabore um comentário crítico/ reflexivo escrito. Em seguida, sentindo-se mais seguro, devido à orientação prévia do professor, o aluno expõe suas impressões de forma oral (OLIVEIRA; SILVA; NETO; VLACH, 2005, p. 73).

O ensino de conceitos auxiliado pelo uso de letras de músicas pode mobilizar as seguintes ações didáticas, considerando a relação entre conceitos científicos e práticas pedagógicas (CAVALCANTI, 1998):

- Propicia atividade mental e física dos alunos, estimulando a interação do aluno com o saber escolar através de seus instrumentais cognitivos (observar, localizar, compreender, descrever, representar). Trata-se de tarefa inicial de audição e análise da música e apropriação de significados que as letras permitem depreender, sugerindo debate sobre essas visões;

- Considera a vivência dos alunos como dimensão do conhecimento, captando o significado que os alunos dão aos conceitos científicos. Nesse estágio, o procedimento de buscar identificar e explicar os processos socioespaciais descritos nas músicas faz o aluno expor seus conhecimentos prévios e tecer relações com o mundo vivido e conhecido;

- Estabelece situações de interação e cooperação entre os alunos, contribuindo para o processo de socialização e desenvolvimento de habilidades por meio de conhecimentos e visões diferentes sobre o mesmo assunto. Neste estágio, é oportuno oferecer alguns questionamentos sobre a letra da música e a percepção de conceito que ela traz, estimulando a interação entre os alunos que podem trabalhar organizados em grupos;

- Conta com a intervenção do professor no processo de aprendizagem dos alunos, colocando problemas e informações para a reconstrução de conteúdos. Com base no encaminhamento do diálogo, o professor pode desafiar os alunos propondo atividades reflexivas a partir de trechos da letra musical, propiciando a construção de sentidos ao texto e seu contexto socioeconômico e espacial;

- Apresenta informações, conceitos e análise de dados, decodificando significações e avaliando criticamente as informações. 0 professor acrescenta à análise da música determinadas informações sobre lugares, regiões e território, sendo elas em gráficos, mapas, fotografias, etc, solicitando aos alunos que extraiam algumas conclusões sobre os mesmos e produzam seu próprio conhecimento; 
- Propicia situações de diálogo entre alunos e destes com o professor, ressaltando-se a importância da interação social para a apropriação em conhecimento sobre as matérias de ensino. Nessa etapa, o professor estimula a construção de conclusões parciais pelos grupos de alunos e busca sistematizá-las em um quadro geral, compartilhando conhecimentos e informações entre grupos;

- Promove a auto e sociorreflexão dos alunos, estimulando o aluno a aprender e direcionar os próprios processos mentais, com a ajuda de palavras ou signos, passos essenciais do processo de formação de conceitos. Nesse momento pode ser feita uma discussão coletiva em sala de aula, oportunidade para a síntese do resultado das atividades e direcionamento do processo de construção de conhecimentos;

- Oferece alternativas ao acompanhamento e controle dos resultados, considerando a natureza do objeto de conhecimento e o tipo de aprendizagem requerida, compreendendo a dinâmica de cada um, suas dificuldades e potencializando as possibilidades de ensino. Ao final do processo de aprendizagem, o professor, como agente ativo, pode fazer o uso de uma avaliação de tipo contínua, observando a participação de cada um dos alunos nas atividades propostas durante todo o período analisado; ou uma avaliação de tipo formativa e sistemática, sugerindo a construção de um texto individual ou coletivo que seja alvo de uma conceituação.

\section{Práticas didáticas com uso de música}

Os Parâmetros Curriculares Nacionais de Ensino Médio (2002) destacam que o conjunto de conceitos-chave da Geografia (paisagem, lugar, território, escala e globalização), além de se constituírem em instrumentos de análise científica do espaço, são elementos norteadores da organização curricular e da definição de competências e habilidades básicas a serem desenvolvidas no Ensino Médio a partir da Geografia.

A título de esclarecimento, alguns dos conceitos-chave listados nos PCNs são considerados, na análise científica da Geografia, mais do que conceitos, são, na verdade, categorias. São eles: espaço, território, região, lugar e paisagem. Segundo Spósito (2004), tanto os conceitos quanto as categorias se colocam como partes essenciais do método científico.

Os conceitos são definidos como noções abstratas ou ideias gerais que designam um objeto ou uma classe de objetos. Os conceitos se colocam no interior do conhecimento científico por envol- verem linguagem, representação e descrição, apresentando uma história dinâmica associada a autores e referenciais científico-filosóficos. A categoria, por sua vez, é mais complexa e contraditória que o conceito, pois designa a unidade de significação de um discurso epistemológico. São os conceitos fundamentais do conhecimento e envolvem juízos, aparecendo como as formas da atividade criadora da ideia, essência das coisas materiais. Resumidamente, podemos dizer que toda categoria é, de alguma forma, um conceito, e nem todo o conceito pode ser considerado, cientificamente, uma categoria.

Na presente análise, utilizaremos as sugestões de conceitos-chave oferecidas nos PCN de Ensino Médio, por duas razões principais: o caráter oficial e abrangente do documento e a utilidade deste estudo em futuras análises e usos em sala de aula, já que as recomendações do currículo nacional aparecem em livros didáticos e demais materiais utilizados pelo professor em situações de aprendizagem.

A escolha das letras de música e sugestões didáticas se baseiam nas experiências docentes do presente autor, em nível de ensino básico (6ํ․ํํㅡ. Ano do EF e 1‥-3․ Ano do EM) e ensino superior. A preocupação principal na escolha das letras foi buscar conciliar o aspecto da popularidade das mesmas, associadas a grupos e músicos conhecidos nacionalmente e o conteúdo delas e sua contribuição ao enriquecimento intelectual dos alunos no trabalho com os conceitos geográficos, evitando-se letras com elementos escatológicos, duplos sentidos de motivação sexual, impregnadas de preconceito e racismo ou inspiradoras de atitudes de violência e intolerância.

Como este estudo representa um ensaio teórico, com ideias e sugestões, manifestamos a necessidade de uma futura aplicação em situações de aprendizagem das atividades sugeridas e, dentro de critérios definidos pelo professor, a possibilidade de que os alunos interajam com o conhecimento através da proposição de letras musicais que manifestem mais concretamente seu cotidiano de vida e seu lugar de identidade, salientando a necessidade de se evitar exageros e atitudes de mau-gosto, sobretudo no ambiente formal de escola.

\section{Situação 1 - Estudo da Paisagem}

Os PCN-EM (2002) utilizam a definição de paisagem como sendo "a unidade do arranjo espacial que a nossa visão alcança, sendo crescentemente de caráter social, pois é formada de movimentos impostos pelo homem através de seu trabalho, cultura e emoção". 
A presente atividade pode ser encaminha-

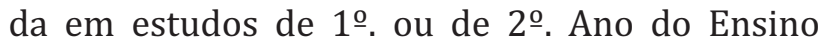
Médio. No $1^{\circ}$. Ano pode ser encaminhada na abordagem da temática "A fisionomia da Crosta terrestre", observando-se os aspectos visíveis artificiais e naturais, e também pode ser realizada quando da abordagem dos temas "A paisagem rural" e a "A paisagem urbana", buscando estabelecer as diferenciações e pontos de aproximação entre esses dois ambientes do espaço geográfico. Além disso, no nível de $2^{\circ}$. Ano EM é possível retomar a letra proposta nos estudos sobre o eixo temático "O território brasileiro: Um espaço globalizado", explorando o quadro de ocupação territorial, nacionalidade e identidade cultural brasileiro.

A letra de música sugerida para análise é "Aquarela Brasileira", composição de Silas de Oliveira e em ritmo de samba-enredo. Trata-se de composição feita para o Carnaval de 1964, como samba-enredo da escola Império Serrano. Essa música ganhou várias interpretações durante os últimos anos e se consagrou como um dos sambas de enredo mais conhecidos de todos os tempos.

A letra da música trata dos Estados brasileiros e vai descrevendo seus elementos, começando do Norte e chegando ao Sudeste, não colocando aspectos sobre a região Sul e seus Estados. Contendo elementos da natureza, objetos técnicos e manifestações culturais, a letra é bastante rica para um estudo da paisagem ou das paisagens do Brasil, considerando seus aspectos concretos e seus elementos de percepção. Trata-se de letra que ressalta as belezas paisagísticas do Brasil, sobretudo as naturais, e serve como elemento motivador para construção e entendimento do conceito de paisagem e sua aplicação em estudos sobre o território brasileiro.

\section{Aquarela brasileira}

Silas de Oliveira

Vejam essa maravilha de cenário

É um episódio relicário, Que o artista, num sonho genial

Escolheu para este carnaval.

Eo asfalto como passarela

Será a tela do Brasil em forma de aquarela.

Caminhando pelas cercanias do Amazonas

Conheci vastos seringais.

No Pará, a ilha de Marajó

Ea velha cabana do Timbó.

Brasília tem o seu destaque

Na arte, na beleza, arquitetura:

Caminhando ainda um pouco mais

Deparei com lindos coqueirais.

Estava no Ceará, terra de irapuã,

De Iracema e Tupã

Efiquei radiante de alegria
Quando cheguei na Bahia...

Bahia de Castro Alves, do acarajé,

Das noites de magia do Candomblé.

Depois de atravessar as matas do Ipu

Assisti em Pernambuco

A festa do frevo e do maracatu.

Feitiço de garoa pela serra!

São Paulo engrandece a nossa terra!

Do leste, por todo o Centro-Oeste,

Tudo ébelo e tem lindo matiz.

Brasil, essas nossas verdes matas,

Cachoeiras e cascatas de colorido sutil

No Rio dos sambas e batucadas,

Dos malandros e mulatas

De requebrosfebris.

E este lindo céu azul de anil

Emoldura em aquarela o meu Brasil

\section{Atividades:}

1 - Audição e leitura/interpretação da música.

2 - Separar os alunos em grupos para o trabalho.

3 - Questionar os alunos sobre a visão de paisagem que traz a letra. Retomar título da música e seu trecho inicial "Vejam essa maravilha de cenário" e estimular manifestação de conhecimentos prévios. 4 - Solicitar a separação dos elementos contidos nas paisagens regionais: classificar em paisagem natural, paisagem humanizada ou cultural (elementos implícitos). Debater a razão dessa divisão e os elementos colocados nas categorias.

5 - Solicitar nova separação dos elementos, agora por estados brasileiros, e dentro deles separar elementos da paisagem natural e cultural. Buscar sintetizar as diferenças e socializar as conclusões.

6 - Levantar mais informações e elementos dos Estados que estão faltando na letra da música, em Atlas, Almanaques ou Internet.

7 - Finalizar atividade com sugestão de dois trabalhos para avaliação: a) uma colagem de imagens e dados estatísticos sobre um mapa em branco do Brasil, apresentando um mosaico da paisagem brasileira, conforme elementos da música e outros levantados em sala de aula; b) elaboração de uma paródia de aquarela brasileira com base no contexto do município em que vivem os alunos, retratando as paisagens dos bairros no lugar dos Estados retratado.

8 - Socialização da produção final entre os alunos, com mediação do professor.

\section{Situação 2 - Estudo do Lugar e dos Lugares}

Os PCN-EM (2002) definem o lugar como sendo a "porção do espaço apropriável para a vida, que é vivido, reconhecido e cria identidade. É aquela porção do espaço com a qual o indivíduo se identifica mais diretamente, guardando formas do 
tempo passado e presente. Nele é que ocorrem as situações de conflito, dominação, resistência e recuperação da vida".

0 estudo dos lugares pode ser encaminhado em diferentes momentos do Ensino Médio. No caso específico das três músicas propostas para aprofundamento do estudo do conceito de lugar, consideraremos alguns temas/conteúdos de 1ㅇ․ Ano do EM ("As conquistas tecnológicas e alteração do equilíbrio natural", "Ações em defesa do substrato natural e da qualidade de vida"), de $2^{\circ}$. Ano do EM ("Paisagem rural e urbana", "Nacionalidade e identidade cultural", "Crescimento e dinâmica populacional no Brasil: Migrações"), e de 3‥ Ano do EM ("Um mundo que se abre: fim da Guerra fria e expansão do capitalismo", "População mundial e migrações").

A música "Lugar nenhum" foi composta e é interpretada pela banda paulistana Titãs, surgida nos anos 1980 e nacionalmente conhecida, seguindo o estilo rock n' roll. A música citada foi gravada para compor o álbum "Go Back", de 1988, e expõe os sentimentos de um cidadão em um mundo capitalista em vias de se globalizar, ou mesmo de um imigrante ou viajante em trânsito pelo mundo.

A música "Sampa", por sua vez, é de autoria e interpretação do músico baiano Caetano Veloso, do estilo MPB (Música Popular Brasileira) e retrata as primeiras impressões de muitos migrantes nordestinos, como o autor, que se depararam e tiveram um estranhamento com a grandeza e dinâmica da metrópole paulistana. Veloso gravou a música "Sampa" em 1978, em seu álbum "Muito-dentro da estrela azulada".

A terceira música faz parte do ideário popular do Nordeste, particularmente do sertão nordestino, com ritmo de baião. Trata-se de "Asa Branca", composição do sanfoneiro e intérprete Luis Gonzaga, junto de seu parceiro, o compositor Humberto Teixeira. A música foi gravada e lançada no ano de 1947 e retrata o flagelo da seca no sertão nordestino através da figura de um retirante-narrador que descreve as intempéries climáticas de seu lugar de vida e o desejo de retornar à sua região após a chuva, para rever a amada.

\section{Lugar nenhum}

Arnaldo Antunes, Tony Bellotto, Marcelo Fromer, Sérgio Britto, Charles Gavin

Não sou brasileiro, Não sou estrangeiro, Não sou brasileiro,

Não sou estrangeiro.

Não sou de nenhum lugar,

Sou de lugar nenhum.Não sou de São Paulo, não sou japonês.

Não sou carioca, não sou português.

Não sou de Brasília, não sou do Brasil.

Nenhuma pátria me pariu.

Eu não tô nem aí.

Eu não tô nem aqui

Sampa

Caetano Veloso

Alguma coisa acontece no meu coração

Que só quando cruza a Ipiranga e a avenida São João

É que quando eu cheguei por aqui eu nada entendi

Da dura poesia concreta de tuas esquinas

Da deselegância discreta de tuas meninas

Ainda não havia para mim Rita Lee

A tua mais completa tradução

Alguma coisa acontece no meu coração

Que só quando cruza a Ipiranga e a avenida São João

Quando eu te encarei frente a frente não vi o meu rosto

Chamei de mau gosto o que vi, de mau gosto, mau gosto

É que Narciso acha feio o que não é espelho

E à mente apavora o que ainda não é mesmo velho

Nada do que não era antes quando não somos mutan-

tesE foste um difícil começo

Afasto o que não conheço

E quem vende outro sonho feliz de cidade

Aprende depressa a chamar-te de realidade

Porque és o avesso do avesso do avesso do avesso

Do povo oprimido nas filas, nas vilas, favelas

Da força da grana que ergue e destrói coisas belas

Da feia fumaça que sobe, apagando as estrelas

Eu vejo surgir teus poetas de campos, espaços

Tuas oficinas de florestas, teus deuses da chuva

Pan-Américas de Áfricas utópicas, túmulo do samba

Mais possível novo quilombo de Zumbi

$E$ os novos baianos passeiam na tua garoa

E novos baianos te podem curtir numa boa

\section{Asa Branca}

Luis Gonzaga e Humberto Teixeira

Quando "oiei" a terra ardendo

Qual a fogueira de São João

Eu perguntei a Deus do céu, ai

Por que tamanha judiação

Eu perguntei a Deus do céu, ai

Por que tamanha judiação

Que braseiro, que fornaia

Nem um pé de "prantação"

Por farta d'água perdi meu gado

Morreu de sede meu alazão

Por farta d'água perdi meu gado

Morreu de sede meu alazão

Inté mesmo a asa branca

Bateu asas do sertão

"Intonce" eu disse, adeus Rosinha

Guarda contigo meu coração

"Intonce" eu disse, adeus Rosinha

Guarda contigo meu coração

Hoje longe, muitas légua 


\section{Numa triste solidão}

Espero a chuva cair de novo

Pra mim vortar pro meu sertão

Espero a chuva cair de novo

Pra mim vortar pro meu sertão

Quando o verde dos teus "óio"

Se "espaiar" na prantação

Eu te asseguro não chore não, viu

Que eu vortarei, viu

Meu coração

Eu te asseguro não chore não, viu

Que eu vortarei, viu

Meu coração

\section{Atividades:}

1 - Conforme a audição e leitura da primeira música, questionar os alunos sobre o tipo de lugar que a música trata. Quais elementos definem o pertencimento a um lugar pela música (nacionalidade, localização) e o que seria o lugar nenhum? Por que o personagem da música diz que não pertence a qualquer lugar?

2 - Reunir os alunos em grupos e sugerir que desenhem e descrevam como seria seu lugar de vida e o que seria um lugar nenhum. Quem viveria nele (moradores da rua, migrantes, refugiados)?

3 - Realizar a audição e análise das músicas "Sampa" e "Asa Branca". Separar em um quadro os elementos que definem os lugares em cada uma das músicas (Cidade e Campo, Sudeste e Nordeste), apontando as diferenças entre esses lugares do ponto de vista de seus objetos naturais/artificiais, da linguagem utilizada e da transmissão de sentimentos dos personagens.

4-Realizar colagens e desenhos retratando os lugares diferenciados anteriormente. Esse trabalho também pode ser feito por meio de charges ou Histórias em Quadrinhos.

5 - Levantar e oferecer mais informações, dados e imagens sobre as regiões contexto das músicas "Sampa" e "Asa Branca", estimulando o debate entre os grupos. Consolidar o quadro de diferenciação anterior.

6 - Para finalização e avaliação, orientar os alunos para elaboração de uma apresentação cênica ou em forma de mural interativo expondo e diferenciando os mosaicos de imagens e símbolos dos lugares que as músicas apresentam. Essa apresentação pode ser para os alunos da mesma sala e também para os demais colegas da escola, estimulando a interação entre eles. Sugere-se o uso de materiais simples para montagem de painéis e cenários, como cartolinas, papelão, recortes de jornais e revistas, giz de cera e lápis de cor, materiais recicláveis, roupas velhas, entre outros.

\section{Situação 3 - Estudo do Território, Escala Geo- gráfica e Globalização}

O termo território aparece nos PCN-EM (2002) como sendo a "porção do espaço definido e delimitado por relações de poder, domínio e apropriação política, econômica ou social". 0 grupo que se apropria de um território e se organiza sobre ele, cria relações de territorialidade, relação essa entre os agentes sociais, políticos e econômicos que interferem na organização do espaço.

A escala em Geografia, segundo os PCN, se divide em duas categorias: a escala cartográfica, que envolve uma relação numérica de proporção entre a realidade concreta e a realidade representada; e a escala geográfica. A escala geográfica, preocupação mais específica dessa análise, é um tipo de "visão relativa a elementos componentes do espaço geográfico, tomada a partir de um direcionamento do olhar científico, procurando responder aos problemas referentes à distribuição dos fenômenos. Trata-se de uma forma de seleção da análise dos fatos geográficos através de níveis e agrupamentos por ordem de grandeza". Comumente, definem-se quatro amplas escalas de análise geográfica: o local, o regional, o nacional e o global.

A globalização, por fim, é referendada pelos PCN como sendo correspondente ao "processo de implementação de novas tecnologias da comunicação e informação que acabaram por criar a intercomunicação entre os lugares em tempo simultâneo. Essas redes técnicas permitem a circulação de idéias, mensagens, pessoas e mercadorias, em um ritmo acelerado, viabilizando a conexão entre os lugares".

Posto isso, sugerimos para este estudo duas letras de música: Disneylândia, dos Titãs, e Parabolicamará, de Gilberto Gil. A letra da música "Disneylândia" novamente é da banda paulistana Titãs. A música foi gravada no disco denominado "Titanomaquia", de 1993, com forte influência do rock mais pesado. Sua letra expõe o contexto atual de integração econômica e de massificação cultural, com simultaneidade de fatos e fluxos de informações dispersas e constantes associadas às tecnologias da mídia e comunicação modernas. Dá ênfase também ao descompasso entre integração econômica e integração política e social, algo que fica claro na última estrofe da letra que remete às desigualdades da divisão internacional do trabalho e as dificuldades impostas aos imigrantes de países mais pobres, sobretudo quando estes são muçulmanos e iraquianos (país-inimigo declarado de George Bush, pai e filho, ex-presidentes estadunidenses).

Já a música "Parabolicamará" é de autoria do compositor, músico e político baiano Gilberto Gil, incluída no álbum homônimo lançado em 1991 e tocada em estilo MPB, com inicialização por berimbau. A letra referida aborda as mudanças na percepção do espaço terrestre face ao aumento na velocidade dos fluxos de informação e nos meios de transportes, considerando-se uma expansão do mundo conhecido com a experiência da simultaneidade.

Esta atividade de análise situar-se-ia melhor em uma sequência didática para $3 \%$. Ano do EM, quando se trabalha no eixo temático proposto 
pelos PCN e denominado "O mundo em transformação: As questões econômicas e os problemas geopolíticos", se desmembrando em vários temas e subtemas, como: redes/ técnicas e fluxos, expansão do capitalismo, desenvolvimento/ subdesenvolvimento, nacionalismos/ separatismos, tensões/ conflitos e guerras, mapas/ gráficos/ indicadores sociais do mundo, a representação do local e do global.

Assim, a sugestão do trabalho com esta música pode ser alocada tanto em início do estudo do eixo temática mencionado, para mobilizar conhecimentos prévios e atrair os alunos para a construção dos conceitos; ou no intermédio e fim, para consolidar alguns conhecimentos construídos por outros procedimentos, exemplificando como estes conhecimentos podem aparecer em outro tipo textual, como a letra de música.

\section{Disneylândia}

Arnaldo Antunes, Sérgio Britto, Paulo Miklos

Filho de imigrantes russos casado na Argentina

Com uma pintora judia,

Casou-se pela segunda vez

Com uma princesa africana no México

Música hindú contrabandiada por ciganos poloneses faz sucesso

No interior da Bolívia zebras africanas

E cangurus australianos no zoológico de Londres.

Múmias egípcias e artefatos íncas no museu de Nova York

Lanternas japonesas e chicletes americanos

Nos bazares coreanos de São Paulo.

Imagens de um vulcão nas Filipinas

Passam na rede de televisão em Moçambique

Armênios naturalizados no Chile

Procuram familiares na Etiópia,

Casas pré-fabricadas canadenses

Feitas com madeira colombiana

Multinacionais japonesas

Instalam empresas em Hong-Kong

E produzem com matéria prima brasileira

Para competir no mercado americano

Literatura grega adaptada

Para crianças chinesas da comunidade européia.

Relógios suiços falsificados no Paraguai

Vendidos por camelôs no bairro mexicano de Los Angeles.

Turista francesa fotografada semi-nua com o namorado árabe

Na baixada fluminense

Filmes italianos dublados em inglês

Com legendas em espanhol nos cinemas da Turquia

Pilhas americanas alimentam eletrodomésticos ingleses na Nova Guiné

Gasolina árabe alimenta automóveis americanos na África do Sul

Pizza italiana alimenta italianos na Itália

Crianças iraquianas fugidas da guerra
Não obtém visto no consulado americano do Egito Para entrarem na Disneylândia

\section{Parabolicamará \\ Gilberto Gil}

Antes mundo era pequeno

Porque Terra era grande

Hoje mundo é muito grande

Porque Terra é pequena

Do tamanho da antena

Parabolicamará

Ê volta do mundo, camará

Ê, ê, mundo dá volta, camará

Antes longe era distante

Perto só quando dava

Quando muito ali defronte

E o horizonte acabava

Hoje lá trás dos montes

dendê em casa camará

Ê volta do mundo, camará

Ê, ê, mundo dá volta, camaráDe jangada leva uma eternidade De saveiro leva uma encarnação

Pela onda luminosa

Leva o tempo de um raio

Tempo que levava Rosa

Pra aprumar o balaio

Quando sentia

Que o balaio ia escorregar

Ê volta do mundo, camará

Ê, ê, mundo dá volta, camará

Esse tempo nunca passa

Não é de ontem nem de hoje

Mora no som da cabaça

Nem tá preso nem foge

No instante que tange o berimbau Meu camará

Ê volta do mundo, camará

Ê, ê, mundo dá volta, camará

De jangada leva uma eternidade

De saveiro leva uma encarnação

De avião o tempo de uma saudade Esse tempo não tem rédea

Vem nas asas do vento

0 momento da tragédia

Chico Ferreira e Bento

Só souberam na hora do destino

Apresentar

Ê volta do mundo, camará

Ê, ê, mundo dá volta, camará

\section{Atividades:}

1 - Realização de audição e leitura inicial das músicas.

2 - Organização da sala em grupos. Questionamentos iniciais sobre o processo inerente à música: como é possível que ele aconteça, quais atividades estão sendo integradas?

3 - Sugestão para elaboração de uma lista inicial, com base na letra da música "Disneylândia", identificando todos os lugares citados e associando-os aos seus respectivos países. Associar esses lugares às atividades que representam na letra (indústria, comércio, serviços, turismo, fenômenos naturais, gastronomia) e representar esses fluxos em um mapa-múndi, com legendas reportando às atividades. Esse mapa será socializado entre os grupos da sala.

4 - A partir de uma definição e explicação sobre o que é "Território", pesquisando seu significado em dicionários, discutir com os alunos o que está acontecendo com as fronteiras territoriais no contexto da música. Quais são as diferentes territori- 
alidades que ela apresenta? Em que momento da música reforça-se a definição de território como um espaço de representação de um poder político? Debater ao fim, se a integração transfronteiriça é para todos os cidadãos do mundo. Depois desse painel, sugerir a construção de textos ou charges que comparem as duas visões: de fim dos territórios (desterritorialização) ou a revalorização das fronteiras políticas e econômicas. 5 - Novamente, buscar trazer uma breve definição de "Escala geográfica", por meio de dicionário e citação textual em lousa, após um levantamento de conhecimentos prévios. Explicar as formas de apreensão do local, regional, nacional e global. Sugerir aos alunos que montem uma tabela e identifiquem na música exemplos de fatos e situações que comecem no local e se direcionem até o global. Exemplo: local (Bairro mexicano de Los Angeles); regional (Baixada Fluminense), nacional (relógios suíços, falsificação no Paraguai) e global (crianças chinesas da comunidade europeia). Os grupos construirão, ao final, um infográfico em círculos concêntricos representativos das escalas geográficas, preenchendo-o com recortes de jornais/revistas, dados estatísticos e desenhos que ilustrem as escalas mencionadas anteriormente.

6 - Por fim, vai-se para construção do conceito de "Globalização". Como é algo inerente à contemporaneidade de muitos alunos, os jovens têm muito a falar e exemplificar sobre o tema. 0 professor pode elencar as palavras que os alunos associarem à globalização em lousa. Após essa discussão inicial, retoma-se a letra da música "Parabolicamará" e coloca-se ao lado dela a imagem de David Harvey com o título "Encurtamento das distâncias" (em anexo). Abre-se um debate sobre o sentido da afirmação mundo pequeno (antes) e Terra grande (antes), e mundo grande (hoje) e Terra pequena (hoje), fazendo uma analogia com a imagem. Comparam-se também os meios de transporte e comunicação e a velocidade crescente deles: jangada, saveiro, avião e onda luminosa, pontuando com as ideias de distante, longe e perto, antigamente e na atualidade. Por fim, solicita-se que os alunos retomem a letra das duas músicas e definam o que vem a ser a globalização, textualmente, apontando elementos dela em sua cidade, tanto dos fluxos de mercadorias e pessoas, quanto das informações e internet, ilustrando o texto com colagens representativas. Termina-se com a socialização das dissertações e sugestão final para que os alunos criem suas letras musicais ou poesias sobre a globalização, remetendo ao seu cotidiano.

7 - A avaliação contínua se dá pelo trabalho em grupo e socialização dos resultados. Ao final, os alunos juntam os trabalhos parciais e montam uma ficha temática com o tema: "Território na Globalização".

\section{Considerações finais}

0 presente ensaio teve por objetivo organizar uma reflexão sobre o ensino de conceitos geográficos, tanto no Ensino fundamental quanto no Ensino médio, e demonstrar como a música pode ser utilizada como ferramenta criativa e socialmente relevante para a aderência dos jovens à aprendizagem de conteúdos geográficos.

Este texto se pautou em uma discussão teórica balizada em autores específicos e no diálogo entre eles e o texto oficial dos PCN, já que este sugere que os conceitos devem aparecer como eixos estruturadores do trabalho com conteúdos, competências e habilidades em sala de aula.

Além disso, buscou-se apresentar suges- tões para aplicações didáticas que façam uso de letras de música para o processo de construção de conceitos, mais particularmente no Ensino médio. Ratificamos novamente o pensamento de que o processo de ensino-aprendizagem de conceitos geográficos deve levar à constituição de uma consciência espacial nos alunos associada à reflexão, interação e elaboração de significados sobre seus espaços e lugares de vivência.

Finalizamos esse estudo com a expectativa de que este seja alvo de futuras aplicações em sala de aula de algumas de suas sugestões de trabalho com letras musicais, no convívio cotidiano dos alunos com os conteúdos geográficos e contando com a intermediação do professor.

Assim, teremos futuramente um cabedal maior de informações para ratificar ou mesmo confirmar ou desconstruir as premissas que pautaram nossas afirmações. Por enquanto, continuamos a apostar na ideia central aqui exposta de que o ensino de conceitos geográficos na escola é algo essencial para formação do aluno, sendo a música um instrumento que pode auxiliar nesse processo.

\section{Referências}

MINISTÉRIO DA EDUCAÇÃO E CULTURA/BRASIL. Secretaria de Educação Média e Tecnológica. Parâmetros Curriculares Nacionais: Ensino Médio. Brasília: MEC/SEMTEC, 2002, p. 275-360.

MINISTÉRIO DA EDUCAÇÃO E CULTURA/BRASIL. Secretaria de Educação Média e Tecnológica. PCN+Ensino Médio: Orientações educacionais complementares aos parâmetros curriculares nacionais em Ciências humanas e suas tecnologias. Brasília: MEC/Semtec, 2002.

MINISTÉRIO DA EDUCAÇÃO E CULTURA/BRASIL. Secretaria de Educação Fundamental. Parâmetros Curriculares Nacionais: Geografia - Ensino de 5a. a 8ạ. Série. Brasília: MEC/SEF, 1998.

CASTELLAR, S. M. V. Alfabetização em Geografia. Espaços da escola, Ed. Unijuí, v. 10, n. 37, 2000, p. 29-46.

CAVALCANTI, L. S. Geografia: Escola e construção de conhecimentos. Campinas: Papirus, 1998.

DAMIANI, A. L. A Geografia e a construção da cidadania. In CARLOS, A. F. A. A Geografia na sala de aula. SP: Contexto, 1999.

OLIVEIRA, H. C. M.; SILVA, M. G.; NETO, A. T.; VLACH, V. R. F. A música como um recurso alternativo nas práticas educativas em Geografia: Algumas reflexões. Caminhos da Geografia, Instituto de Geografia/UFU, v. 8, n. 15, jun. de 2005, p. 73-81. 
VESENTINI, J. W. Educação e Ensino de Geografia: Instrumento de dominação e/ou libertação. In: CARLOS, A. F. A. (org). A geografia em sala de aula. SP: Contexto, 1999.
VIANA, A. M. A música como recurso didático em Geografia: Uma abordagem da Geografia no cotidiano. In REGO, N.; SUERTEGARAY, D. M. A.; HEIDRICH, A., Geografia e Educação: Geração de ambiências. Porto Alegre: Ed.UFRGS, 2000.

\section{ANEXO 1 - A compressão do espaço pelo tempo e o encurtamento das distâncias}

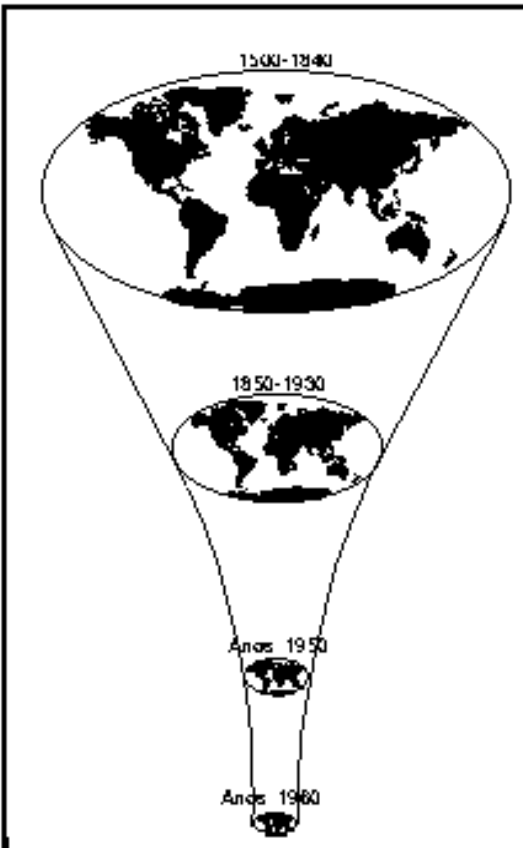

1500-1840 A melhor média de velocidade das carnuagens e dos barcos a vela era de $16 \mathrm{~km} / \mathrm{h}$

1850-1930 As locomotivas a vapor alcançavam em média $100 \mathrm{~km} / \mathrm{h}$; os barcos a vapor, $57 \mathrm{~km} / \mathrm{h}$.

Anos 1950 Aviōes a propulsão: $480-640 \mathrm{~km} / \mathrm{h}$.

Anos 1960 Jatos de passageiros: $800-1100 \mathrm{~km} / \mathrm{h}$.

(Adaptado de: D. HARVEY, A condị̆äo pósmadema, Ediọ̆es Loyola, p. 200, 1989) 


\title{
Knowing new sounds, new spaces: the music as an element for teaching lessons of Geography
}

\begin{abstract}
The article reflects the practice of teaching Geography in Basic Education, with proposes the music as an element in teaching Geography classes. Given the amount of information that can be found in other sources than the classroom, students should be attracted to it, with a didactic methodology that does not get stuck to traditional forms of education, making it more attractive to student. Considering that music has a great relation to different spaces, both by topics that refer his lyrics as the linkage the sounds that go with it have with different locations, we know the music a way to develop in students a reflection of the different spaces. It is noteworthy, too, that music is an element very present in the daily life of students. We propose a work in the classroom through music, providing work exemplifications and suggestions for themes that can be widely exploited in the classroom, as support for the work of Geography teacher.
\end{abstract}

Keywords: Teaching. Learning. Geography. Music. Methodologies.

\section{Conociendo nuevos sonidos, nuevos espacios: la música como elemento didáctico para las clases de geografía}

Resumen: El artículo reflexiona sobre la práctica de la enseñanza de la geografía en la educación básica, proponiendo la música como un elemento en la enseñanza en la clase de Geografía. Dada la cantidad de información que se puede encontrar en otras fuentes distintas de la clase, los estudiantes deben ser atraídos por el mismo, con algunas metodologías de enseñanza que no se parecen a las formas tradicionales de educación, por lo tanto cada vez más atractivo para los estudiantes. Teniendo en cuenta que la música tiene una gran relación con los diferentes espacios, tanto de los temas que tienen que ver con sus letras como en el vínculo que los sonidos que lo acompañan tienen a diferentes lugares, encontramos en la música una forma de desarrollar en los estudiantes una reflexión de los diferentes espacios. Es de destacar, también, que la música es un muy presente en la vida cotidiana de los estudiantes. Se propone un trabajo en la clase con la música ofreciendo ejemplificaciones de trabajo y sugerencias de temas que pueden ser ampliamente explotados en la clase, para apoyar el trabajo del profesor de Geografía.

Palabras-clave: Enseñanza. Aprendizaje. Geografía. Música. Metodologías. 